\title{
"How old do you feel today at work?" Work-related drivers of subjective age in the workplace
}

\author{
Theresa Goecke and Florian Kunze \\ Chair for Organisational Studies, University of Konstanz, Konstanz, Germany
}

\begin{abstract}
Most Western societies face the challenge of steadily ageing workforces. In recent decades, research on ageing has intensively focused on the subjective age concept to understand the challenges and risks of increasingly ageing workforces. Nevertheless, the subjective age construct is subject to several conceptual uncertainties, namely, regarding its stability and potential work-specific drivers of subjective age. We address these limitations by a) investigating the stability of subjective age in a worker sample, and b) identifying work-specific drivers (e.g., negative work events, positive work events, work stress) of subjective age perceptions. Building on social identity and lifespan theories, we test our conceptual assumptions with an online sample of 168 U.S. employees, applying growth curve modelling in a daily diary study over one workweek. Results indicate that subjective age is a mutable construct and varies between- and within-person in the course of a workweek. We identify positive work events and work stress as between-person drivers and negative work events as a within-person driver of subjective age. We discuss theoretical implications of these findings as well as consequences for practitioners.
\end{abstract}

\section{KEYWORDS}

Subjective age; stability; work stress; work events; daily diary

\section{Introduction}

In almost all Western societies, population and, in particular, workforces are ageing at fast pace (e.g., Bureau, 2008; OECD, 2015). In Germany, for instance, one-third of the general population will be older than 64 years in 2060 (Bundesministerium des Inneren, 2011); further, the workforce participation of employees between 60 and 67 years has almost doubled between 2007 and 2018 (Bundesagentur fuer Arbeit, 2019). As a consequence, organizations and executives urgently need advice on the consequences and potential intervention strategies for an increasingly ageing workforce.

In the field of management and organization behaviour, research on the demographic is currently dominated by studies on the effects of chronological age on work outcomes, which is not surprising, as an employee's chronological age is a key variable for decisions about promotion, learning opportunities, and retirement (Crumpacker \& Crumpacker, 2007). These established practices often result in discrimination and stigmatization of older and younger workers (Kunze, Boehm, \& Bruch, 2011; Posthuma \& Campion, 2009), leading to the question at which age a worker is assumed to be old. Although the ADEA (U.S. Age Discrimination in Employment Act of 1967) and further researchers (Bourne, 1982; Warr, 2000) consider workers over the age of 40 to be old, others argue that a clear and generalized cut-off at a certain age is not possible. The definition of what is "old" depends on several contextual factors, such as cultural embeddedness, the demographic change and composition, or the work domain, e.g., a professional athlete is considered as "old" at a different age as a politician (e.g. Dordoni \& Argentero, 2015; Ng \& Feldman, 2008).
In this study, we argue that, instead of solely relying on chronological age, researchers and practitioners in the field of management and organization behaviour should, rather, consider an employee's subjective age, when thinking about managing the demographic change of the workforce. Subjective age refers to a person's perception about one's own age (Montepare, 2009) and is, according to Kastenbaum, Derbin, Sabatini, and Artt (1972), a multidimensional construct including four dimensions: feel age, look age, do age, and interest age. In many research studies, it is assessed with a relative subjective age score, indicating the difference score between chronological age and the subjective age of an individual (Stephan, Caudroit, \& Chalabaev, 2011; Teuscher, 2009).

In the past decades, researchers from various fields, e.g., gerontology (Diehl et al., 2014), social and developmental psychology (Barak, 2009), and even organization research (BarnesFarrell, Rumery, \& Swody, 2002) identified several positive effects of feeling younger than one's chronological age. In gerontological research, a lower relative subjective age is, for example, related to better physical (Caudroit, Stephan, Chalabaev, \& Le Scanff, 2012) and mental functioning (Keyes \& Westerhof, 2012), and even predicts longevity (Westerhof et al., 2014). Relative subjective age offers a more holistic perspective on ageing in the workplace: It shows relationships towards several variables important for organization sustainability and success, such as stress and strain perception at work (Barnes-Farrell \& Piotrowski, 1991; Barnes-Farrell et al., 2002), work motivation (Akkermans et al., 2016)m and even organizational performance (Kunze, Raes, \& Bruch, 2015). Akkermans et al. (2016) showed that, by including relative subjective age in the equation, chronological age effects vanish, i.e., do no longer 
predict work motivation. These findings indicate that, beyond chronological age, relative subjective age is a relevant concept to predict health-, motivation-, and performance-related outcomes in the organizational context (Akkermans et al., 2016; Kunze et al., 2015).

Beyond the differing effects of chronological age and relative subjective age on potential outcome, a further distinctive characteristic between these two age concepts refers to the malleability of the constructs. While chronological age is a steadily growing concept over the life-course, indicating the distance to a person's date of birth, relative subjective age is a potential malleable factor, and numerous environmental factors in an employee's work context might affect his or her subjective perceptions. Thus, the first and main aim of our paper is to investigate the stability of relative subjective age in the course of a workweek, which is one of the research gaps currently identified in this research area (Kotter-Gruehn, Kornadt, \& Stephan, 2015; Rudolph, Kunze, \& Zacher, 2019).

Assuming that relative subjective age varies over time raises questions on what drives relative subjective age variability. Several (quasi-) experimental studies showed that it is possible to modify (relative) subjective age perceptions (see, e.g., Dutt \& Wahl, 2017; Eibach, Mock, \& Courtney, 2010; Geraci, De Forrest, Hughes, Saenz, \& Tirso, 2018). Furthermore, Kotter-Gruehn, Neupert, and Stephan (2015) showed that, in a daily diary study with retirement home residents (age range: 60 to 90 years), relative subjective age fluctuates in the course of a week, and Armenta, Scheibe, Stroebe, Postmes, and Van Yperen (2018) demonstrated a similar variability of relative subjective age ${ }^{1}$ within a workweek in a sample of older workers (age range: 50 to 70 years). Both current studies tried to identify first work and nonwork factors that might affect individual's subjective age fluctuations. In their gerontological sample, Kotter-Gruehn et al. (2015) identified health as a daily (nonwork) driver of subjective age; further, Armenta et al. (2018) showed that negative work events affect subjective age perceptions. ${ }^{2}$ Although these studies offer first insights into which variables drive subjective age perceptions, the generalizability of the findings is limited in respect to the sample composition and the consideration of independent variables. Thus, our second aim focuses on the identification of within- and between-person drivers of relative subjective age in the work context. We assume that organization interventions, such as stress perceptions or specific work events, both triggered through specific organization cultures, HR management practices, or leadership behaviours, might modify relative subjective age perceptions and thereby influence potential personal and organization outcomes.

Overall, with this paper, we contribute to the current research on subjective age in the workplace in two ways: First, we investigate the stability of subjective age in a worker sample including the full age-range of employees between 18 and 76 years of 168 employees with five measurement points over a whole workweek, offering a more complete picture of subjective age stability in the organization context. Second, we add on the findings of Armenta et al. (2018), considering not only negative work events; we also research positive work events and work stress as potential through the lenses of life-stages theories (Heckhausen, Wrosch, \& Schulz, 2010) and social identity-theory
(SIT, Tajfel \& Turner, 1986) as drivers of relative subjective age variation over the course of a workweek. Extending the previous diary studies (Armenta et al., 2018; Kotter-Gruehn et al., 2015), we are also the first, to the best of our knowledge, to clearly distinguish within-persons and between-persons fluctuations over the course of one workweek. With these two major contributions, we also aim to offer insights for practitioners to tailor organization interventions to alter employees' subjective age perceptions. This can, in turn, help organizations to sustain a healthy, motivated, and productive ageing workforce. Additionally, we hope to motivate further research on work-related drivers of subjective age to understand which work designs and work conditions are appropriate for a sustainable workforce in an ageing society and to gain more knowledge on the nature on subjective age in the work context. In the following, we will first outline our argumentation for the general stability of subjective age before we, second, introduce the three potential subjective age drivers: negative work events, positive work events, and work stress.

\section{Theoretical outline}

\section{Stability of relative subjective age in the course of a workweek}

Existing research treats subjective age as a relatively stable personal characteristic (see the argumentation of Kotter-Gruehn et al., 2015). Nevertheless, social identity theory (SIT, Tajfel \& Turner, 1986) assumes that one's identity and self-perception is a variable concept (Stets \& Burke, 2000; Stryker \& Burke, 2000; Tajfel \& Turner, 1986). This builds on the propositions about a person's reflection of the self, embedded in a social context and in an interaction with the environment, i.e., a person's identity has multiple facets, and every person holds several different identities (Tajfel \& Turner, 1986). If and how strong an individual demonstrates or activates one or the other identity depends on the salience and relevance of a certain identity in a specific situation (Brenner, Serpe, \& Stryker, 2014; Stets \& Burke, 2000; Tajfel \& Turner, 1986). Following, we assume that the (relative) subjective age perception (also called "age identity"; Armenta et al., 2018) varies within a person with the salience and relevance of age in different situations/contexts (Brenner et al., 2014). For example, a person might feel older after paying the senior price to enter a museum, as age becomes a salient category in this situation. In line with this idea, Diehl et al. (2014) developed the theoretical concept of age awareness assuming subjective age perceptions vary with the relevance of age in a given situation/context.

Beyond social identity arguments, lifespan theories can also be used to explain short-term variation in subjective age perceptions. These theories assume that, over a person's life course, individuals tend to invest resources to obtain control over their environment (Heckhausen et al., 2010); further, as older individuals have lower levels of primary control capacities, due to certain deficits such as a decline of information-processing capacities, they tend to invest more in motivational and compensatory processes, as they get older, for example to "feel younger" to sustain a general sense of control (Zacher \& Rudolph, 2019). Recent findings indicate that, in particular, varying levels of occupational future time perspectives (OFTP), defined as the 
perception of an employee's remaining time in the work context (Lang \& Carstensen, 2002; Zacher \& Frese, 2009), affect subjective age perceptions, with employees perceiving a long and open OFTP feeling younger and employees with a limited OFTP feeling older. In consequence, it seems reasonable to assume that certain concrete work events, which make one's age more or less salient, can change the OFTP and, in consequence, the relative subjective age perceptions.

First, empirical evidence supports these ideas, showing that confronting people with age-related information influences their subjective age perceptions (Eibach et al., 2010; Hess, Auman, Colcombe, \& Rahhal, 2003). Furthermore, Montepare (1996) found that the closer the birthday, the older people feel. Nevertheless, explicit empirical investigations on the variability of subjective age remain limited. An exception is the study by Kotter-Gruehn, Neupert et al. (2015) showing relative subjective $\mathrm{age}^{3}$ fluctuations in a daycare context with the elderly. Their findings suggested that the relative subjective age is not a stable concept and varies on a daily basis (KotterGruehn, Neupert et al., 2015). Furthermore, Armenta et al. (2018) investigated relative subjective age in a sample of older workers and found a significant amount of withinperson variance of relative subjective age, suggesting that it is worth to study daily fluctuations of relative subjective age.

One characteristic in the study designs of KotterGruehn, Neupert et al. (2015) and Armenta et al. (2018) calls for deeper examination into the stability of relative subjective age in the work context. Both studies considered old (employees aged 50 to 70 years; Armenta et al., 2018) and elderly participants (retirement home inhabitants aged 60 to 90 years; Kotter-Gruehn, Neupert et al., 2015) and, thus, did not consider the relative subjective age stability of younger participants/employees, who might have a higher likelihood to age identity changes, as their identity formation is far more ambiguous compared with that of chronological old employees (Armenta et al., 2018). As Galambos, Turner, and TiltonWeaver (2005) argued and showed that relative subjective age perceptions change with increasing age and might even have different meanings in different age groups. The older individuals are, the lower is their relative subjective age. These findings indicate that it is relevant to consider both, older and younger employees, to gain a holistic perspective on (relative) subjective age stability. Based on the theoretical arguments and the first empirical insights from the existing diary studies, we would assume that:

Hypothesis 1: Individuals' relative subjective age shows significant within-person variability in the course of a workweek.

\section{Work-related drivers of relative subjective age}

Assuming that relative subjective age varies on a short-term and even daily basis raises the question about triggers of relative subjective age fluctuations, i.e., which cues make people feel younger or older than others (between-person variations) and which daily conditions/situations affect daily relative subjective age variability of a person (within-person variations). In line with the previously introduced arguments from social identity theory
(SIT, Tajfel \& Turner, 1986) and lifespan theories (e.g., Heckhausen et al., 2010), we will develop hypotheses for three potential workrelated drivers, namely, negative work events, positive work events, and perceived stress. All the following hypotheses are based on the idea that situational and daily characteristics (Eibach et al., 2010; Kotter-Gruehn, Neupert et al., 2015), socalled proximal reference points, might modify relative subjective age perceptions on a short-term basis and refer to withinperson relative subjective age fluctuations and also explain between-person differences of subjective age perceptions.

\section{Role of negative work events}

Following the argumentation of Armenta et al. (2018) and in line with SIT (Tajfel \& Turner, 1986) and lifecourse arguments (Heckhausen et al., 2010), we assume that negative events at work can raise negative self-perceptions in respect to one's age and/or open or limited OFTP that might drive fluctuations in subjective age perceptions. These arguments have been tested in a general nonwork-related setting, thus showing that the confrontation with negative age stereotypes (Eibach et al., 2010) or negative age-related feedback (Geraci et al., 2018) affects individual's (relative) subjective age. Armenta et al. (2018) extended these findings to the workplace and showed that age-related work events (i.e., age declines or age discrimination) drive daily relative subjective age perceptions. Furthermore, recent studies suggest that even general mood inductions can affect (relative) subjective age perceptions (Dutt \& Wahl, 2017). The authors argued that negative events can cause negative mood, which functions as a heuristic for evaluation judgements (see Dutt \& Wahl, 2017; also see Schwarz \& Clore, 1983, 2003) and, thus, affect (relative) subjective age perceptions (Dutt \& Wahl, 2017). Translated to the work context, we assume that negative work events induce negative mood and thus increase employees' (relative) subjective age perception (see Dutt \& Wahl, 2017), which is potentially also mediated through a different OFTP (Zacher \& Frese, 2009) of employees perceiving more or less negative events. In particular, we investigate general negative events at work, e.g., interpersonal conflicts, negative feedback and discrimination (see Appendix A) as drivers of (relative) subjective age variability. In line with other daily diary studies (e.g., Sonnentag \& Kuehnel, 2016) and the approach of Armenta et al. (2018), we differentiate between- and within-person drivers of relative subjective age testing our hypotheses (also see Ohly, Sonnentag, Niessen, \& Zapf, 2010). Our assumption is that negative work events can be a driver of between-person differences, as employees, who constantly experience negative events, should feel older than employees with less negative experience. Additionally, we also assume that individuals should feel relatively older on days when experiencing more negative events, thus proposing a within-person effect. In summary, we propose the two following hypotheses:

Hypothesis 2a: Daily negative work events account for between-person variability in relative subjective age and lead to older relative subjective age perceptions.

Hypothesis 2b: Daily negative work-events account for within-person short-term variability in relative subjective age in the course of a workweek and lead to older relative subjective age perceptions. 


\section{Role of positive work events}

Beyond negative work events, we also investigate positive work events as potential drivers of relative subjective age perceptions. In line with the ideas of positive psychology (Seligman \& Csikszentmihalyi, 2014), we assume that positive work events (e.g., accomplishing a task, receiving positive feedback; see Appendix A for details) affect age perceptions. Recent ageing studies showed that several positive variables, e.g., high life satisfaction (Montepare \& Lachman, 1989), good physical (Caudroit et al., 2012; Stephan, Sutin, \& Terracciano, 2015) and psychological health (Keyes \& Westerhof, 2012), are related to a younger relative subjective age. Nevertheless, most studies, which tried to modify relative subjective age perceptions, used negative stimuli for their experimental manipulation, e.g., negative age stereotypes (Eibach et al., 2010) or negative mood (Dutt \& Wahl, 2017). Geraci et al. (2018) showed that cognitive testing increases subjective age perceptions; they also tested if positive performance feedback can buffer these negative effects. The authors did not find a moderation effect of positive performance feedback. Kotter-Gruehn, Neupert et al. (2015) tested, in their daily diary study, if positive and negative affect drive relative subjective age perception and found only a significant effect of negative but not of positive affect. Nevertheless, social identity theory (Stets \& Burke, 2000; Stryker \& Burke, 2000; Tajfel \& Turner, 1986) postulates that various events can initiate age-related heuristics and increase the salience of an individual's age identity (also see the argumentation of Dutt \& Wahl, 2017). It also seems plausible that positive work events might create a more open OFTP (Zacher \& Frese, 2009) and, thus, reduce the perceptions of an individual's subjective age. Similar to the negative events, we propose that perceiving positive work events can drive both betweenperson differences, with employees (constantly) experiencing positive feedback and emotions feeling younger compared with employees with limited positive experience and withinperson differences with positive events changing the daily individual perceptions of subjective age. Consequently, we hypothesize that positive work events affect between- and within-person variability in relative subjective age:

Hypothesis 3a: Daily positive work events account for between-person variability in relative subjective age and lead to younger relative subjective age perceptions.

Hypothesis 3b: Daily positive work events account for within-person short-term variability in relative subjective age in the course of a workweek and lead to younger relative subjective age perceptions.

\section{Role of work stress}

Work stress is one of the most studied variables with respect to employees' health and performance in the work context (e.g., Demerouti, Bakker, Nachreiner, \& Schaufeli, 2001; Nixon, Mazzola, Bauer, Krueger, \& Spector, 2011). Previous research consistently showed the negative consequences of stress at work (e.g., Johnstone \& Feeney, 2015), as stress is well known to accelerate ageing processes (Sapolsky, Krey, \& McEwen, 1986). Based on SIT (Tajfel \& Turner, 1986), we assume that a rising level of stress increases the relevance and salience of age-related cognitions (Brenner et al., 2014) and might also lead to limited OFTP (Zacher \& Frese, 2009), both triggering higher relative subjective age perceptions. Barnes-Farrell et al. (2002) supported this assumption, showing that stress is related to higher relative subjective age perceptions (also see Foster, Hagan, \& Brooks-Gunn, 2008; Schafer \& Shippee, 2010). Nevertheless, these studies are limited to their cross-sectional design and are neither able to identify causality nor withinperson effects of relative subjective age. Because work is one of the major sources of stress in the work-age population, and several stressors change and accumulate day to day, we assume that stress serves as both between- and within-person predictor of relative subjective age. In line with identity relevance and salience (Brenner et al., 2014), we expect that people who experience a higher level of stress at work feel older than people with lower stress levels do (between-person variability). Furthermore, we assume that a person feels older on days with higher stress level and feels younger when experiencing less stress (within-person variability). Consequently, we propose:

Hypothesis 4a: Daily work-stress perceptions accounts for between-person variability in relative subjective age in the course of a workweek.

Hypothesis 4b: Individuals' daily work-stress perceptions accounts for within-person short-term variability in relative subjective age in the course of a workweek.

\section{Methods}

\section{Sample and procedure}

We recruited a U.S. online sample from the Amazon Mechanical Turk (MTurk) platform in seven waves over a period of one week. We ran seven survey waves on this platform, including one presurvey and one general survey, followed by five surveys from Monday to Friday.

In the first presurvey wave $(N=460)$, we selected participants according to the following selection criteria: Employees should be employed with a minimum of 30 hours per week (see, e.g., Barber \& Jenkins, 2014) and work a maximum of onethird of their working hours from home. Individuals who met these criteria $(N=221)$ received the second survey (general survey), consisting of several general measures (demographics, employment situation, subjective health and well-being, etc.). Two hundred nine individuals fully completed this survey and therefore obtained access to the subsequent daily surveys from Monday to Friday designed to capture employees' evaluations of their workday as well as several subjective health and wellbeing measures, including daily relative subjective age measures. The daily surveys ran from 5 p.m. EST until 6 a.m. EST the next day to ensure that individuals reflect on their workday and offer a certain amount of time flexibility for the participants. We sent out daily reminders and rewarded participants on a daily basis. Participants accessed all surveys from the MTurk website, which redirected them to the survey platform questback. Participants received $\$ 0.50$ USD for participating in the presur- 
vey, \$2 USD for the general second survey and \$1 USD for each completed daily survey. In order to motivate participants to complete all surveys and reduce the dropout, we offered a \$2 USD bonus when participants completed all surveys. From Monday through Friday, the sample size ranged from 146 (response rate: $66 \%$ ) to 168 (response rate: $74 \%$ ) participants per day. Overall, participants could gain a maximum of 9.50 USD for full participation. ${ }^{4}$ We illustrate the overall study design and data collection points in Figure 1.

Following the recommendations of Ployhart and Vandenberg (2010), we excluded all participants who completed less than three daily surveys, resulting in a final sample size of 168 (76\%). One hundred nine individuals (49\%) participated in all surveys. The final sample $(N=168)$ consisted of $54.5 \%$ male participants with an average age of 38.85 years $(\mathrm{SD}=10.89$ ). The sample included $83.2 \%$ Caucasian American; 6.0\% Asian/Pacific American; 5.4\% Black or African American; and $2.4 \%$ Hispanic or Latino. One-point-two percent held a doctoral degree, $18.6 \%$ a master's degree, and $42.5 \%$ a bachelor's degree. Six percent held a technical degree, $15.6 \%$ attended some college, $10.8 \%$ finished high school and $4.8 \%$ took some graduate courses. As to the employment structure, $59.3 \%$ worked in the private sector, while $39.5 \%$ worked in the public sector, and $1.2 \%$ worked in multiple organizations.

\section{Measures}

For the analyses, we used data from the five daily surveys from Monday to Friday (see Figure 1) as well as gender and chronological age information from the general survey. In the analysis of daily relative subjective age stability $(\mathrm{H} 1)$, we used time (linear and quadratic term) and the dependent variable relative subjective age. For the identification of potential drivers of daily relative subjective age, we investigated negative work events $(\mathrm{H} 2 \mathrm{a}, \mathrm{H} 2 \mathrm{~b})$, daily positive work events $(\mathrm{H} 3 \mathrm{a}, \mathrm{H} 3 \mathrm{~b})$, and daily work stress $(\mathrm{H} 4 \mathrm{a}$, $\mathrm{H} 4 \mathrm{~b}$ ), and, including the seven control variables (chronological age, gender, daily subjective physical and mental health, daily pain, daily positive and negative affect, daily life satisfaction). Because we were interested in the daily fluctuations of relative subjective age and potential daily predictors, we framed all measurements as day-specific items, in case they were not daily measures by origin. For example, we adapted the original feel-age item of Kastenbaum et al. (1972) to "Today, I feel as though I am ... years old." (for similar adaption method, see Kotter-Gruehn et al., 2015). Because Gable and Reis (2010) suggested that daily assessments should not exceed five to seven minutes in total, we followed the recommendations of Ohly and Schmitt (2015) and chose single- or reduced-item measures from established scales for some of the variables.

\section{Core variables}

\section{Daily relative subjective age}

We measured daily subjective age by adapting the multidimensional measurement from Kastenbaum et al. (1972; for similar adaption method, see Kotter-Gruehn, Neupert et al., 2015). The four-item measurement represents four aspects of subjective age: the feel age ("Today, I feel as though I am ... years old"), the look age ("Today, I look as though I am ... years old"), the do age ("Today, I do most things as though I were ... years old"), and the interest age ("Today, my interests are mostly those of a person that is ... years old"). From of the four items, we constructed one overall daily subjective age score as well as the daily relative subjective age score (difference between daily subjective and chronological age). ${ }^{5}$ The reliability values for the daily relative subjective age measurement from Monday to Friday ranged between $a=.83$ and $a=.88$. We ran a confirmatory factor analysis (CFA) in order to validate that we summarize the four aspects of relative subjective age (feel age, look age, do age, interest age) to one overall relative subjective age score. The model with all four relative subjective age aspects loading on one common factor $\left[X^{2}(2)=1.74 ;\right.$ n.s. $]$ shows good model fit indices (CFI = 1.00; NFI = .98; RMSEA = .00; AIC = 17.74). Thus, we assume that it is appropriate to apply the overall relative subjective age score in our analyses.

\section{Time}

Time represents the five assessment points from Monday to Friday. Following the recommendation of KotterGruehn, Neupert et al. (2015), we assigned the numbers 0 to 4 to the five measurement times to reflect the time order of the survey assessments with the first survey as zero point.

\section{Work-specific variables}

\section{Daily negative work events}

We asked participants how often a certain event occurred during the past workday to measure daily negative events at work ( 1 = "did not occur" to 4 = "occurred a lot"; Bono, Glomb, Shen, Kim, \& Koch, 2013). The daily negative work events scale consisted of four items (Cronbach's alphas between $\alpha=.72$ and $a=.89$ ); an example item asked, "Did you receive information that negatively affected your work schedule, duties or pay?" We present all items of this measure in Appendix A.

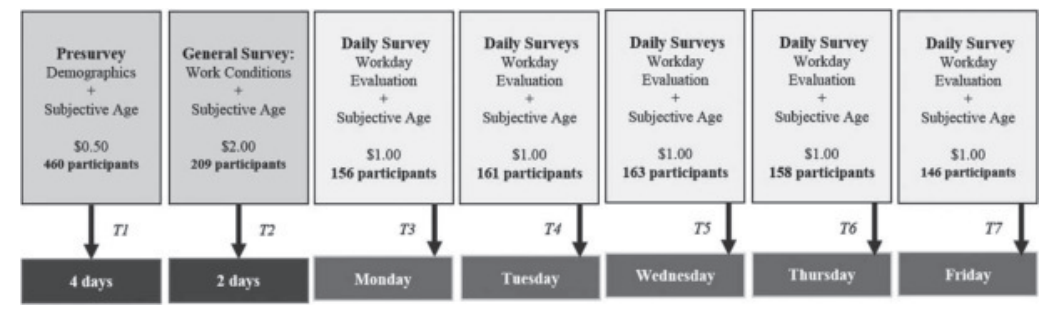

Figure 1. Study design and data collection points. 


\section{Daily positive work events}

We measured daily positive and negative events at work according to Bono et al. (2013) by asking participants, "How often did the following events/situations occur during your past work day?" ( 1 = "did not occur" to 4 = "occurred a lot"). Daily positive events at work consisted of five items, for example: "Did you accomplish what you hoped to?" Cronbach's alphas ranged between $a=.69$ and $a=.78$ (Monday to Friday). Appendix A shows all five positive work event items.

\section{Daily work stress}

We asked participants to rate their daily stress at work according to the following statement: "My past work day had been stressful" ( 1 = "strongly disagree" to 5 = "strongly agree"; Bono et al., 2013).

\section{Controls}

Because several researchers find different effects of (relative) subjective age for young and old individuals (Galambos et al., 2005), we asked employees to report their chronological age with their exact date of birth. We then translated this information in years (numbers with two decimal places). Women and men significantly differ in (relative) subjective age perceptions based on their social roles (Barrett, 2005; Sato, Shimonaka, Nakazato, \& Kawaai, 1997). Therefore, we controlled for gender when testing for Hypotheses $3 \mathrm{a}$ to $5 \mathrm{~b}$. Gender was a dummy variable: Employees indicated if they were male (0) or female (1). For the investigation of the work-specific predictors ( $\mathrm{H} 3 \mathrm{a}$, $\mathrm{H} 3 \mathrm{~b}, \mathrm{H} 4 \mathrm{a}, \mathrm{H} 4 \mathrm{~b}, \mathrm{H} 5 \mathrm{a}, \mathrm{H} 5 \mathrm{~b}$ ), chronological age, gender, daily subjective physical and mental health, daily pain, daily positive affect, daily negative affect, and daily life satisfaction served as control variables because we want to show the effects of workspecific predictors beyond health- and affect-related variables.

\section{Daily subjective physical health}

To measure employees' daily subjective physical health, we adapted the one-item general self-rated health (GSRH) measurement (DeSalvo et al., 2006). Participants rated the question, "Today, would you say your physical health is ... ?" (1 = "excellent," 2 = "very good," 3 = "good," 4 = "fair," 5 = "poor").

\section{Daily subjective mental health}

We assessed daily subjective mental health, adapting the measurement of the Canadian Community Health Survey (CCHS; Statistics Canada, 2015). We asked participants "Today, would you say your mental health is ... ?" ( 1 = "excellent," 2 = "very good," 3 = "good," 4 = "fair," 5 = "poor").

\section{Daily pain}

Participants indicated their level of perceived pain, replying to the following question: "What number between 0 (no pain) and 100 (unbearably heavy pain) best describes your average level of bodily pain during the past work-day?" (KotterGruehn, Neupert et al., 2015).

\section{Daily positive/negative affect}

We measured daily positive and negative affect using a shortversion of the positive affect/negative affect scale (PANAS)
(Watson, Clark, \& Tellegen, 1988; for further applications, see Bono et al., 2013; Kotter-Gruehn, Neupert et al., 2015), consisting of 10 positive affective states and 10 negative affective states. We asked participants to rate the 20 emotions ("How much did you feel this way today?") on a five-point scale ( 1 = "very slightly or not at all" to $5=$ "extremely"). Daily positive affect contained, e.g., the adjectives "enthusiastic" (Item 1) and "interested" (Item 2), while we measured negative affect with, e.g., the adjectives "upset" (Item 13) and "distressed" (Item 14). In our analysis, we excluded two items in the daily positive affect scale (Item 4 "excited" and Item 5 "inspired"), as their errors correlated with the errors of Item 1 ("enthusiastic"). We furthermore excluded two negative affect items (Item 11 "scared" and Item 19 "irritable") because their errors correlated substantially with Items 12 ("afraid") and 16 ("nervous"). Thus, for consistency, we calculated average scores for daily positive affect (PA) and daily negative affect (NA) based on the reduced scales. The reduced scales evinced a better model fit than the full scale $\left(\Delta x^{2}(72)=488.39\right.$, $p \leq .001 ; \Delta \mathrm{AIC}=500.39)$. The Cronbach's alpha values for the corrected daily positive affect scale (PA) ranged between $a=.91$ and $a=.95$ (Monday to Friday) and between $a=.86$ and $a=.92$ (Monday to Friday) for the corrected daily negative affect scale (NA).

\section{Daily life satisfaction}

We measured daily life satisfaction with an adapted version of one item from Diener, Emmons, Larsen, and Griffin (1985). Participants evaluated their agreement to the following statement: "Today, I am satisfied with my life" ( 1 = "strongly disagree" to 7 = "strongly agree").

\section{Analyses}

The complexity and longitudinal character of the data required prior analysis to check for data quality and ensure interpretability of the findings (e.g., test for systematic dropout). Thus, we present first pre-analyses in the next paragraph before proceeding to the main analysis, in which we test all hypotheses and explain our analysis strategies.

\section{Pre-analyses}

To ensure that systematic dropouts (Eibach et al., 2010) did not affect our results, we analysed if the missing data were completely at-random (MAR). To test this assumption, we ran T-tests between the participants who participated three times $\left(\mathrm{N}_{3}\right.$ : minimal inclusion criteria) and those who participated five times ( $\mathrm{N}_{5}$ : maximal participation option). We did not find any significant differences for chronological age $\left(\mathrm{N}_{3}: M=36.93\right.$, $t=-.87 ; \mathrm{N}_{5}: M=39.62 ; t=-.83 ; F=.12$, n.s.; $\left.\mathrm{Cl}[-8.86 ; 3.47]\right)$ nor for daily relative subjective age $\left(\mathrm{N}_{3}: M=-2.09, t=.33 ; \mathrm{N}_{5}\right.$ $M=-2.84 ; t=.57 ; F=2.43$, n.s.; $\mathrm{Cl}[-3.73 ; 5.23])$, indicating that we do not have systematic dropout and can assume the missing data to be MAR.

Additionally, in alignment with other daily-diary studies (e.g., Sonnentag \& Kuehnel, 2016), we tested if the time of survey completion (participants had 13 hours to complete the survey) had an influence on the results. Therefore, we ran a regression analysis for the Monday survey data, indicating 
that time of completion did not affect the dependent variable (daily relative subjective age; $B=1.03 ;$ n.s.; $95 \% \mathrm{Cl}[.00 ; .00]$ ).

\section{Main analyses}

According to the intended two main research contributions, we divided the analyses into three main parts. In the first part, we investigated the daily relative subjective age trajectories of employees in the course of one workweek ( $\mathrm{H} 1)$ : We tested an intercept-only model, including only daily relative subjective age and calculated the within- and between-person variance with intra-class correlations for multilevel models (Raudenbush \& Bryk, 2002). Second, we ran growth curve models in STATA 14 using random-coefficient modelling (Bryk \& Raudenbush, 1992; Rabe-Hesketh \& Skrondal, 2008) to identify between-person drivers of relative subjective age ( $\mathrm{H} 2 \mathrm{a}$ : negative work events, H3a: positive work events, H4a: daily work stress; see Table 3). Furthermore, we applied multilevel random coefficient modelling to identify within-person drivers of daily relative subjective age, running separate analyses for the three variables $(\mathrm{H} 2 \mathrm{~b}$ : negative work events, $\mathrm{H} 3 \mathrm{~b}$ : positive work events, $\mathrm{H} 4 \mathrm{~b}$ : daily work stress; see Table 3). We treated the within-person variables as first-level predictors and the between-person variables as second-level predictors. We included eight control variables in all analyses to detect effects beyond chronological age, gender, health variables (daily subjective physical and mental health, pain), and affect-related variables (daily positive and negative affect, daily life satisfaction).

\section{Results of main analyses}

Table 1 illustrates descriptive and correlation results of all measures, including inter- and intra-individual standard deviation (SD). As expected, chronological age shows strong correlations with daily subjective age $(r=.80 ; p<.001)$ and daily relative subjective age $(r=-.61 ; p<.001)$. Beyond a significant correlation with daily subjective mental health $(r=-.17$; $p<.05)$, chronological age does not show significant correlations with the involved variables. Contrastingly, daily relative subjective age is correlated with daily work stress $(r=.29$; $p<.001)$ and daily subjective physical $(r=.24 ; p<.001)$ and mental $(r=.35 ; p<.001)$ health as well as daily pain $(r=-.29$; $p<.001)$ and daily positive affect $(r=-.27 ; p<.001)$. Furthermore, daily relative subjective age significantly correlates with daily positive work events $(r=-.17 ; p<.05)$ and daily negative affect $(r=.18 ; p<.05)$.

\section{Relative subjective age stability and drivers}

To assess Hypothesis 1, we test the stability of relative subjective age in the course of the workweek. We first estimate an intercept-only model to identify the within- and betweenperson variances of relative subjective age with intra-class correlations (ICC) for multilevel models (Raudenbush \& Bryk, 2002). The ICC for daily relative subjective age is .76, indicating that $76 \%$ of the variance in relative subjective age variance is due to between-person differences, while $24 \%$ of variance lies within-persons. These numbers justify the multilevel growth

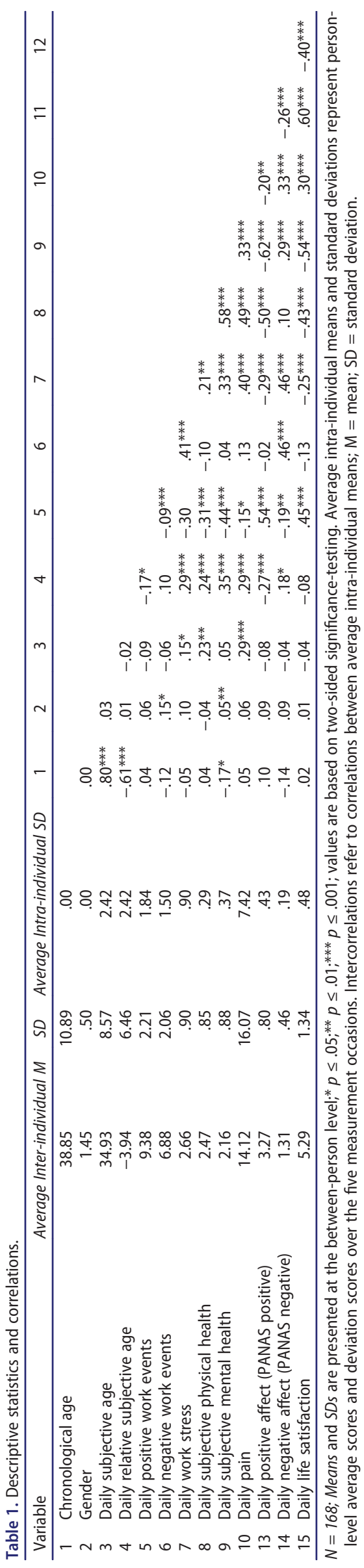


curve modelling approach and the consideration of betweenand within-person variance in the analyses. ${ }^{6}$

\section{Work-specific drivers of daily relative subjective age}

To investigate how daily negative work events $(\mathrm{H} 2 \mathrm{a}, \mathrm{H} 2 \mathrm{~b})$, daily positive work events $(\mathrm{H} 3 \mathrm{a}, \mathrm{H} 3 \mathrm{~b})$, and daily work stress ( $\mathrm{H} 4 \mathrm{a}$, H4b) affect daily relative subjective age, we apply multilevel random coefficient modelling, according to the recommendations made by Raudenbush and Bryk (2002) and similar to those by Kotter-Gruehn, Neupert et al. (2015). We report the findings for the between-person work-specific predictors (see Table 2) before presenting the within-person work-specific predictors of daily relative subjective age in the course of the workweek (see Table 3).

\section{Between-person drivers of relative subjective age}

We identify between-person predictors of relative subjective age with random coefficient modelling, ${ }^{7}$ including daily positive work events, daily negative work events, and daily work stress as work-specific predictors, with chronological age, gender, daily subjective physical and mental health, daily pain, daily positive and negative affect, and daily life satisfaction as controls (see Model 3, Table 2). Contrary to Hypothesis 2a, the daily negative work events coefficient $(\mu=-.05$; $\mathrm{SE}=.06$; n.s.) is not significant. Nevertheless, in line with Hypothesis 3a, daily positive work events $(\mu=-.15 ; \mathrm{SE}=.06 ; p<.01)$ is a significant between-person predictor of daily relative subjective age with an observable significant coefficient. We find similar results for daily work stress $(\mu=.40 ; \mathrm{SE}=.14 ; p<.01)$, supporting Hypothesis 4 a (see Model 3 in Table 2). ${ }^{8}$ Results indicate that employees who experience more positive work events and less work stress feel younger compared with employees experiencing less positive work events and more work stress.

\section{Within-person drivers of relative subjective age}

We test within-person predictors of daily relative subjective age, including interaction terms (linear and quadratic timeterm $\mathrm{x}$ predictor) for each of the three predictors (daily negative work events, daily positive work events, daily work stress) separately (see Table 3). First, we add the interaction terms between the linear-time term and (daily) negative work events as well as the quadratic-time term and (daily) negative work events (Model 1, Table 3). We find a marginally significant linear interaction term $(\mu=-.20 ; \mathrm{SE}=.10 ; p \leq .10 ; \mathrm{Cl}=[.00 ; .40])$ and a nonsignificant quadratic interaction term $(\mu=-.04 ; \mathrm{SE}=.02$; ns.; $\mathrm{Cl}=[-.09 ; .01])$, suggesting that (daily) negative work events might account for (daily) relative subjective age variability in the course of a workweek (support for $\mathrm{H} 2 \mathrm{~b}$ ). Second, we include the daily positive work events interaction terms (linear and quadratic) in Model 2 (Table 3). The results show that the quadratic interaction term for daily positive work events is not significant ( $\mu=-.07 ; \mathrm{SE}=.10 ; \mathrm{ns}$; $\mathrm{Cl}=[-.26 ; .12])$, indicating that (daily) positive work events are not a within-person predictor of (daily) relative subjective age, in turn rejecting Hypothesis $3 \mathrm{~b}$. Third, we include the linear and quadratic interaction terms with daily work stress in Model 3 (Table 3). None of the interaction terms are significant (see Model 3, Table 3). Because daily work stress does not function as a withinperson driver of daily relative subjective age in the course of a workweek, we cannot support Hypothesis 4b.

Overall, these findings indicate that, on days with more negative work experience, employees feel older than on days with fewer negative work events. Because the linear interaction is only marginally significant, we have to interpret the support for Hypothesis $2 b$ carefully.

\section{Discussion}

In this paper, we extend the literature on subjective age stability and subjective age drivers in the workplace in at least two ways. First, we extend the findings of Kotter-Gruehn, Neupert et al. (2015) and Armenta et al. (2018), demonstrating in a sample of 168 U.S. workers (aged between 21 and 79 years) that $76 \%$ of relative subjective age variance originates from between-person variance, while $24 \%$ leads back to withinperson variance. Thus, our results suggest that relative subjective age is not an immutable, stable construct but reflects a partially time- and situation-dependent construct. This is in line with Montepare (2009) who argued that proximal events or situations affect individuals' subjective age perceptions. Following the argumentation of Armenta et al. (2018), identity salience postulated by the SIT (Tajfel \& Turner, 1986), varies over time and situations and, consequently, influences subjective age perceptions. We extend this contribution of Armenta et al. (2018), showing similar effects in a worker sample representing a full age range of the working age from 18 to 76 years.

Second, we expand Armenta's (2018) approach to identify negative work events as a driver of relative subjective age variability, identifying further relative subjective age drivers by a) specifying the measure of negative work event $(\mathrm{H} 2 \mathrm{a}$, $\mathrm{H} 2 \mathrm{~b})$; b) testing positive work events ( $\mathrm{H} 3 \mathrm{a}, \mathrm{H} 3 \mathrm{~b})$; and c) work stress $(\mathrm{H} 4 \mathrm{a}, \mathrm{H} 4 \mathrm{~b})$ as between- and within-person drivers of relative subjective age. We demonstrate these effects beyond chronological age, gender, daily subjective physical and mental health, daily pain, daily positive and negative affect and daily life satisfaction. Our results indicate that negative work events function as within-person drivers of relative subjective age (but not as between-person driver), while positive work events and work stress affect between-person drivers of subjective age (but not within-person drivers). Thus, our study contributes to the literature related to if and how relative subjective age is mutable through work characteristics. This suggests that executives and HR managers might be able to actively affect employees' subjective age and thereby profit from positive subjective age effects, i.e., good health (Caudroit et al., 2012; Stephan, Chalabaev, Kotter-Gruehn, \& Jaconelli, 2013) reduced short-term absenteeism (Goecke \& Kunze, 2018), or increased organization performance (Kunze et al., 2015).

\section{Theoretical implications}

Subjective age received increasing attention in ageing research over the past decade, and even organization behaviour research started to consider this concept in their studies. Researchers gained various interesting findings about (relative) 


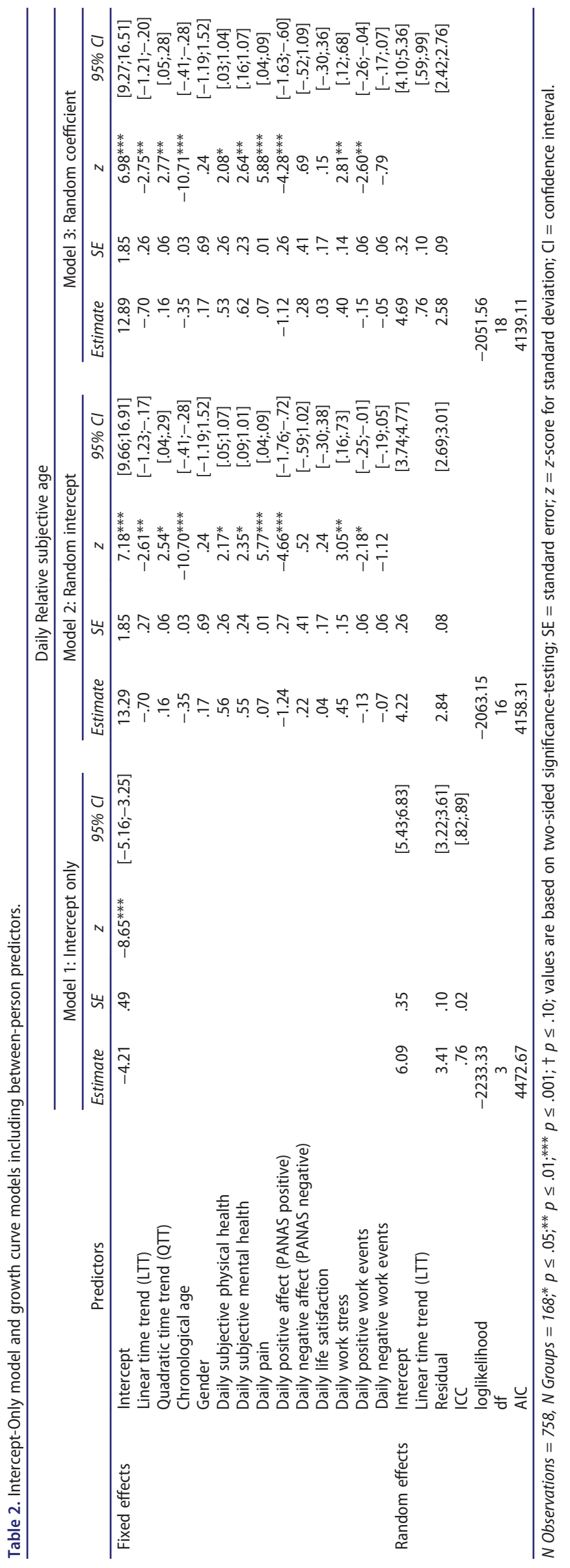




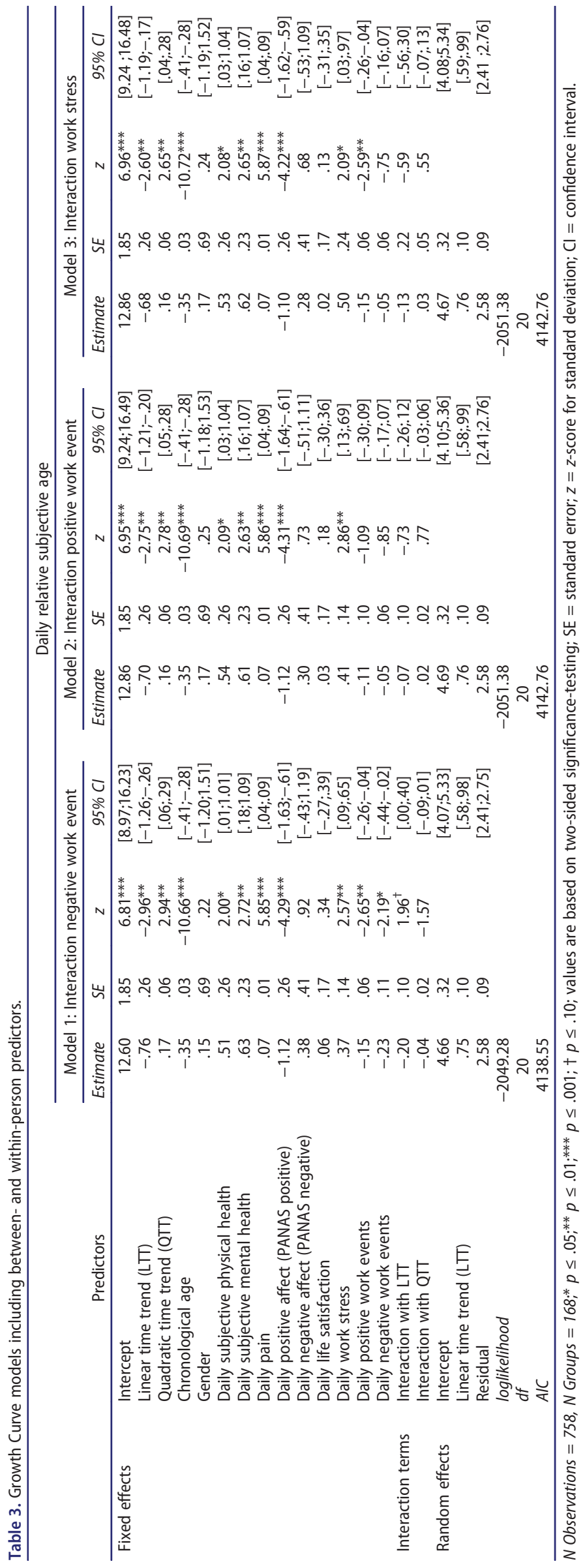


subjective age correlates, like physical and cognitive functioning (Stephan, Caudroit, Jaconelli, \& Terracciano, 2014; Stephan et al., 2013), mental health (Keyes \& Westerhof, 2012), and longevity (Westerhof et al., 2014) in the gerontological context, and organization performance (Kunze et al., 2015), work stress (Barnes-Farrell \& Piotrowski, 1991), and short-term absenteeism (Goecke \& Kunze, 2018) in the work context. Almost all of these studies treat (relative) subjective age as an immutable stable construct that does not vary over time (e.g., see Barak \& Stern, 1986; Barnes-Farrell \& Piotrowski, 1989). Nevertheless, Galambos et al. (2005) argued that subjective age perception changes over the lifespan, and Montepare's (2009) subjective age framework suggested that both distal (i.e., family status, chronical health problems) and proximal (i.e., imminent birthday, short-term sickness) events or cues affect individual's subjective age. Experimental studies demonstrate that certain variables shape (relative) subjective age perceptions, e.g., negative mood (Dutt \& Wahl, 2017), performance feedback (Geraci et al., 2018), and the confrontation with age stereotypes (Eibach et al., 2010). Though only a few studies investigate subjective age variability/stability and drivers with longitudinal data designs, such study designs offer better arguments to assume causality between two or more variables. One of these exceptions is Kotter-Gruehn, Neupert et al. (2015), showing that (relative) subjective age varies significantly over a week in a gerontological sample (between 60 and 96 years old). We investigate the stability of (relative) subjective age in a full range age sample (between 23 and 79 years old) in an organization context. Our results further support that subjective age varies within individuals in the course of a workweek; in addition, we show this trend even in a sample that is more representative for the whole workforce (age range 15 to 64; OECD, 2018). Consequently, it is valid to assume that (relative) subjective age varies both between- and within-person. This is consistent with SIT (Tajfel \& Turner, 1986), assuming that a person holds multiple identities or roles, which activate depending on their relevance and salience in a specific context (Stryker \& Burke, 2000; Tajfel \& Turner, 1986). This might call for a revaluation of many subjective age studies, which mostly conceptualize (relative) subjective age as a relatively stable variable (see, e.g., Barak \& Stern, 1986; Stephan et al., 2011). If relative subjective age fluctuates over conditions and time, cross-sectional (relative) subjective age studies are limited to the study conditions and thus represent only an excerpt of (relative) subjective age perceptions. With our results, we stress that future research should consider the methodological needs of studying (relative) subjective age and take the value of shortterm perspectives into account. This approach allows a more accurate understanding of the role of (daily) relative subjective age for potential antecedents or outcomes.

That subjective age varies over short time frames implies that certain contextual aspects drive the variability of (relative) subjective age perceptions. SIT (Tajfel \& Turner, 1986) suggests that individual (relative) subjective age perceptions (also called age identity) are more salient and relevant in some situations and contexts than in others (Stryker \& Burke, 2000; Tajfel \& Turner, 1986). Furthermore, life course theories (Heckhausen et al., 2010) can also be used to argue for varying subjective age perceptions based on different occupation future time perspectives (OFTP) of individuals. Thus, these situations and contexts can drive (relative) subjective age perceptions (Armenta et al., 2018). The longitudinal studies investigating subjective age stability identified the first drivers of (relative) subjective age. Kotter-Gruehn, Neupert et al. (2015) show that an individual's daily health status affects daily relative subjective age; further, Armenta et al. (2018) reveal that, in the work context, negative work events drive daily relative subjective age perceptions. We extend these findings, demonstrating that, beyond demographic (chronological age, gender), healthrelated (Kotter-Gruehn, Neupert et al., 2015), and affect-related (Dutt \& Wahl, 2017; Miche et al., 2014) variables, concrete negative work events (i.e., "Did you receive negative feedback or criticism/complaints?" see Appendix A) affect within-person relative subjective age, and that positive work events and work stress functions as drivers of between-person relative subjective age perceptions. Overall, the assumption that certain contextual and situational variables trigger and drive (relative) subjective age perceptions sets limits to the interpretation of many previous subjective age studies. Thus, those studies, which treat (relative) subjective age as a stable variable, are limited to one specific setting at one point in time. Our results, in line with Kotter-Gruehn, Neupert et al. (2015) and Armenta et al. (2018), promote future research on subjective age to a) consider the variable nature of subjective age and apply longitudinal study designs, and b) pay attention to the contexts of subjective age measures and anchor their interpretations to these contexts and time-points. Moreover, our study calls for further investigations on (relative) subjective age drivers, in order to gain more clarity about potential contextual and timedependent effects on (relative) subjective age.

\section{Practical implications}

Apart from the theoretical implications, our findings offer several interesting insights for practitioners in public and private organizations. First, we demonstrate that employees' relative subjective age perceptions vary in the course of a workweek (H1). This finding is of particular interest for executives and HR representatives, as it shows that relative subjective age is not predetermined. Rather, it is modifiable through organization and managerial interventions. Thus, as opposed to chronological age, which inevitably increases in many workforces, subjective age is not determined by the years passing. This offers the possibility to modify employees' (relative) subjective age to benefit from the potential positive outcomes for individuals and organizations, e.g., health (e.g., Caudroit et al., 2012), shortterm absenteeism (Goecke \& Kunze, 2018), and organization performance (Kunze et al., 2015).

Our results of (relative) subjective age drivers $(\mathrm{H} 3 \mathrm{a}, \mathrm{H} 3 \mathrm{~b}$; $\mathrm{H} 4 \mathrm{a}, \mathrm{H} 4 \mathrm{~b} ; \mathrm{H} 5 \mathrm{a}, \mathrm{H} 5 \mathrm{~b}$ ) offer insights into potential departure points for interventions to modify (relative) subjective age. We demonstrate that individuals who experience more positive work events ( $\mathrm{H} 3 \mathrm{a}$ ) and less stress $(\mathrm{H} 4 \mathrm{a})$ feel younger (betweenperson drivers). Moreover, day-to-day variability of relative subjective age results from the daily experience of negative events at work ( $\mathrm{H} 2 \mathrm{~b}$; within-person predictor). Consequently, organization functionaries can influence the subjective age perceptions of their employees, thus emphasizing positive work 
events, e.g., establish regular positive events at work, such as short social events (Item 4 daily positive work events scale; e.g., common coffee break; free ice cream dessert). Furthermore, avoiding excessive work stress can prevent employees from feeling old, which typically results in negative individual and organization outcomes. On a daily basis, organization interventions should avoid an accumulation of negative work events, such as negative feedback, being treated disrespectfully, or experiencing work-related conflicts. Thereby, organizations can prevent negative health and performance consequences of increasing (relative) subjective age. In sum, the outlined results, together with the previous investigations of subjective age drivers, enable organizations to identify potential intervention strategies and actively manage employees' subjective age and thereby might contribute to a successful management of the demographic change.

\section{Limitations and future research perspectives}

Our study design and data have several strengths, e.g., the daily-diary approach with five measurement points. Nevertheless, we want to mention limitations resulting from our sampling approach and discuss potential biases in the data. First, our data stems from an Mturk sample and therefore might not be representative for the overall U.S. workforce population. According to the Bureau of Labour Statistics (2015), 57.7\% of the U.S. working population is male, with a median age of 42.3 years (occupational and industry sector). Seventy-nine percent of the US labour population is White (including Caucasian and Hispanics), $12.0 \%$ is African American, 6.0\% Asian American, 1.0\% American Indian and Alaska Natives, and $1.0 \%$ Hawaiian/Pacific Islander. Specifically, the sample has a higher percentage of White workers (83.2\% Caucasian American; $2.4 \%$ Hispanics or Latinos) and a lower percentage of Black or African American workers (5.4\%). Furthermore, the sample is slightly younger (38.85 years) than the average $U$. S. working population. This comparison shows that our sample is not perfectly representative; neither does it differ from the actual demographics. Consequently, we do not expect strong biases caused by the lack of rigid representativeness. ${ }^{9}$

Besides concerns about the sampling approach, we have to consider that the data are solely based on self-reports and therefore suffer from the same-source bias. Although we had no opportunity to mirror participants' responses with external reports (e.g., colleagues, managers, family), we argue that the nature of our research goal allows and requires self-reported data. Our approach is in line with other daily-diary studies relying on self-reports (see, e.g., Conway \& Briner, 2002; Miche et al., 2014). Nevertheless, future research might investigate how external age evaluation perceptions change based on external factors such as seniority, tenure, or authority within an organization. Furthermore, objective-outcome variables like performance ratings might offer an interesting basis in which to understand the effects of (relative) subjective age in organizations.

As it is not a purpose of this paper, we do not focus explicitly on the mechanisms underlying the predictor/relative subjective age relationship. We extend the idea that, besides distal cues, proximal cues influence (daily) relative subjective age perceptions (Montepare, 2009) to the assumption that daily cues trigger daily variability in relative subjective age perceptions (Kotter-Gruehn, Neupert et al., 2015). Nevertheless, we do not measure the cognitive mechanisms that might underlie the connection between daily cues and daily relative subjective age perceptions (e.g., intense elaboration of age-related introspection, stronger awareness for age-related self-information, etc.). As cognitive mechanisms are typically difficult to study through online surveys, we would like to encourage experimental researchers to take a deeper look, in a laboratory context, into the cognitive mechanisms that bridge cues and relative subjective age perceptions.

Furthermore, we see strong potential in the investigation of relative subjective age over even smaller time intervals than on a daily basis. Measuring relative subjective age in immediate time-closeness to these cues might allow us to understand the immediate self-evaluation processes underlying the formation of the relative subjective age a bit better.

\section{Conclusion}

This paper offers conceptual clarifications on the concept of relative subjective age and addresses several methodological and structural gaps in the current debate on ageing in the workplace. We investigate the short-term variability and potential within- and between-person predictors of subjective age and thereby demonstrate the relevance of daily-diary approaches in subjective age research. Our findings show that relative subjective age is a valid construct, and we identify both between- and within-person predictors of (daily) relative subjective age in the course of a workweek. In doing so, we emphasize the relevance of relative subjective age in the organization context. New organization perspectives on ageing not only have the potential to keep an ageing workforce healthy and productive but also to contribute to more sustainable societal approaches to the demographic-change debate. We encourage researchers to consider relative subjective age in order to gain a more holistic understanding about its nature and its role in both daily well-being and performance as well as the general risks and potential gains for our societies.

\section{Notes}

1. The authors use the term "subjective age bias" (SAB) for what we call relative subjective age. Nevertheless, we use the term relative subjective age in this paper, as this is the more common expression (e.g., see Kotter-Gruehn, Neupert et al., 2015; Kunze et al., 2015).

2. The authors postulate subjective age and age-group identification as moderators in the relationship between negative work events and daily affect and cognitive engagement.

3. Relative subjective age represents the difference score between chronological age and subjective age, showing if a person feels older or younger than his/her chronological age. Negative values (low relative subjective age) indicate the number of years a person feels younger than the chronological age, while positive values indicate the number of years a person feels older than the chronological age.

4. We chose the above-mentioned payment method and system following the recommendation of several articles analysing MTurk samples and their motivation (e.g., Berinsky, Huber, \& Lenz, 2012; Buhrmester, Kwang, \& Gosling, 2011; Paolacci, Chandler, \& Ipeirotis, 2010). Accordingly, we set a compensation amount that is over the 
average amount paid on MTurk. Furthermore, we considered the bonus procedure in order to increase the likelihood of ongoing or frequent participation.

5. Negative values (low daily relative subjective age) indicate the number of years that a person feels younger than the chronological age at a specific day, while positive values indicate the number of years that a person feels older than the chronological age at a specific day.

6. To understand the within- and between-person variance, we estimate one model with the linear- and one model adding the quadratic time coefficient. Results show that the quadratic time coefficient is significant $(\mu=.24 ; p \leq .001)$ and shows better model fit [log likelihood (5) $=-2226.18$; AIC $=4462.37$ ] compared with the model, including only the linear time coefficient [log likelihood (4) $=-2231.10 ; \mathrm{AIC}=4470.20 ; \Delta$ likelihood-ratio $X^{2}(1)=9.84$, $\mathrm{p} \leq 01 ; \Delta \mathrm{AIC}=7]$. Therefore, we run all further analyses with the quadratic time coefficient.

7. We test if the random-coefficient model (Model 3, Table 2 ) is superior to the random-intercept model (Model 2, Table 2) with a significant model improvement $\left[\Delta \operatorname{lr} X^{2}(2)=23.20 ; \Delta A I C=19.20\right.$; $p \leq .001$ ]. Consequently,

we apply random coefficient modelling for all further analyses.

8. Robustness checks indicate that findings are consistent when calculating with or without control variables (chronological age, gender, daily subjective physical health, daily subjective mental health, daily pain, daily positive affect, daily negative affect, daily life satisfaction). Results are available upon request.

9. MTurk is an efficient and cost-saving tool to obtain access to a large number of potential participants, which received increasing attention in the last decade for empirical research (Berinsky et al., 2012 Buhrmester et al., 2011; Goodman, Cryder, \& Cheema, 2013). We chose this platform because it offers a reliable sample of the $U$. S. workforce population, independent from organization affiliation. Buhrmester et al. (2011) characterize MTurk as more representative as normal online samples, offering reliable results comparable with results from tradition assessment methods (Goodman et al., 2013; Paolacci et al., 2010)

\section{Disclosure statement}

No potential conflict of interest was reported by the authors.

\section{References}

Akkermans, J., de Lange, A. H., van der Heijden, B. I. J. M., Kooij, D. T. A. M. Jansen, P. G. W., \& Dikkers, J. S. E. (2016). What about time? Examining chronological and subjective age and their relation to work motivation. Career Development International, 21, 419-439.

Armenta, B. M., Scheibe, S., Stroebe, K., Postmes, T., \& Van Yperen, N. W. (2018). Dynamic, not stable: Daily variations in subjective age bias and age group identification predict daily well-being in older workers. Psychology and Aging, 33, 559-571.

Barak, B. (2009). Age identity: A cross-cultural global approach. International Journal of Behavioral Development, 33, 2-11.

Barak, B., \& Stern, B. (1986). Subjective age correlates: A research note. The Gerontologist, 26, 571-578.

Barber, L. K., \& Jenkins, J. S. (2014). Creating technological boundaries to protect bedtime: Examining work-home boundary management, psychological detachment and sleep. Stress and Health, 30, 259-264.

Barnes-Farrell, J. L., \& Piotrowski, M. J. (1989). Workers perception of discrepancies between chronological age and personal age - You're only as old as you feel. Psychology and Aging, 4, 376-377.

Barnes-Farrell, J. L., \& Piotrowski, M. J. (1991). Discrepancies between chronological age and personal age as a reflection of unrelieved worker stress. Work \& Stress, 5, 177-187.

Barnes-Farrell, J. L., Rumery, S. M., \& Swody, C. A. (2002). How do concepts of age relate to work and off-the-job stresses and strains? A field study of health care workers in five nations. Experimental Aging Research, 28, 87-98.

Barrett, A. E. (2005). Gendered experiences in midlife: Implications for age identity. Journal of Aging Studies, 19, 163-183.

Berinsky, A. J., Huber, G. A., \& Lenz, G. S. (2012). Evaluating online labour markets for experimental research: Amazon.com's Mechanical Turk. Political Analysis, 20, 351-368.

Bono, J. E., Glomb, T. M., Shen, W., Kim, E., \& Koch, A. J. (2013). Building positive resources: Effects of positive events and positive reflection on work stress and health. Academy of Management Journal, 56, 1601-1627.

Bourne, B. (1982). Effects of aging on work satisfaction, performance and motivation. Aging \& Work, 51, 37-47.

Brenner, P. S., Serpe, R. T., \& Stryker, S. (2014). The causal ordering of prominence and salience in identity theory: An empirical examination. Social Psychology Quarterly, 77, 231-252.

Bryk, A. S., \& Raudenbush, S. W. (1992). Hierarchical linear models for social and behavioural research: Applications and data analysis methods. Newbury Park, CA: Sage.

Buhrmester, M., Kwang, T., \& Gosling, S. D. (2011). Amazon's Mechanical Turk: A new source of inexpensive, yet high-quality, data? Perspectives on Psychological Science, 6, 3-5.

Bundesagentur fuer Arbeit. (2019). Situation von Aelteren [Situation of the elderly]. Retrieved from https://statistik.arbeitsagentur.de/ StatischerContent/Arbeitsmarktberichte/Personengruppen/generischePublikationen/Aeltere-amArbeitsmarkt.pdf

Bundesministerium des Inneren. (2011). Demografiebericht: Bericht der Bundesregierung zur demografischen Lage und künftigen Entwicklung des Landes. [Demography-Report of the federal government on the demographic situation and future development of the country]. Retrieved from https://www.pkv.de/w/files/politik/studien/demografie bericht-26-10-11.pdf

Bureau of Labour Statistics. (2015). Labour force characteristics. Retrieved from https://www.bls.gov/cps/demographics.htm\#certs_licenses

Bureau, P. R. (2015). Aging in the United States. Population Bulletin, 70, 1-19.

Caudroit, J., Stephan, Y., Chalabaev, A., \& Le Scanff, C. (2012). Subjective age and social-cognitive determinants of physical activity in active older adults. Journal of Aging and Physical Activity, 20, 484-496.

Conway, N., \& Briner, R. B. (2002). A daily diary study of affective responses to psychological contract breach and exceeded promises. Journal of Organisation Behavior, 23, 287-302.

Crumpacker, M., \& Crumpacker, J. M. (2007). Succession planning and generational stereotypes: Should HR consider age-based values and attitudes a relevant factor or a passing fad? Public Personnel Management, 36, 349-369.

Demerouti, E., Bakker, A. B., Nachreiner, F., \& Schaufeli, W. B. (2001). The job demands-resources model of burnout. Journal of Applied Psychology, 86, 499-512.

DeSalvo, K. B., Fisher, W. P., Tran, K., Bloser, N., Merrill, W., \& Peabody, J. (2006). Assessing measurement properties of two single-item general health measures. Quality of Life Research, 15, 191-201.

Diehl, M., Wahl, H.-W., Barrett, A. E., Brothers, A. F., Miche, M., Montepare, J. M., ... Wurm, S. (2014). Awareness of aging: Theoretical considerations on an emerging concept. Developmental Review, 34, 93-113.

Diener, E., Emmons, R. A., Larsen, R. J., \& Griffin, S. (1985). The satisfaction with life scale. Journal of Personality Assessment, 49, 71-75.

Dordoni, P., \& Argentero, P. (2015). When age stereotypes are employment barriers: A conceptual analysis and a literature review on older workers stereotypes. Ageing International, 40, 393-412.

Dutt, A. J., \& Wahl, H.-W. (2017). Feeling sad makes us feel older: Effects of a sad-mood induction on subjective age. Psychology and Aging, 32, 412-418.

Eibach, R. P., Mock, S. E., \& Courtney, E. A. (2010). Having a "senior moment": Induced aging phenomenology, subjective age, and susceptibility to ageist stereotypes. Journal of Experimental Social Psychology, 46, 643-649.

Foster, H., Hagan, J., \& Brooks-Gunn, J. (2008). Growing up fast: Stress exposure and subjective "weathering" in emerging adulthood. Journal of Health and Social Behavior, 49, 162-177. 
Gable, S. L., \& Reis, H. T. (2010). Good news! Capitalizing on positive events in an interpersonal context. In M. P. Zanna \& M. P. Zanna (Eds.), Advances in experimental social psychology (Vol. 42, pp. 195-257). San Diego, CA: Academic Press.

Galambos, N. L., Turner, P. K., \& Tilton-Weaver, L. C. (2005). Chronologica and subjective age in emerging adulthood: The crossover effect. Journal of Adolescent Research, 20, 538-556.

Geraci, L., De Forrest, R., Hughes, M., Saenz, G., \& Tirso, R. (2018). The effect of cognitive testing and feedback on older adults' subjective age. Aging, Neuropsychology, and Cognition, 25, 333-350.

Goecke, T. F. E., \& Kunze, F. (2018). The contextual role of subjective age in the chronological age/absenteeism relationship in blue and white collar teams. European Journal of Work and Organisation Psychology, 27, 1-15.

Goodman, J. K., Cryder, C. E., \& Cheema, A. (2013). Data collection in a flat world: The strengths and weaknesses of Mechanical Turk samples. Journal of Behavioral Decision Making, 26, 213-224.

Heckhausen, J., Wrosch, C., \& Schulz, R. (2010). A motivational theory of life-span development. Psychological Review, 117, 32-60.

Hess, T. M., Auman, C., Colcombe, S. J., \& Rahhal, T. A. (2003). The impact of stereotype threat on age differences in memory performance. The Journals of Gerontology Series B: Psychological Sciences and Social Sciences, 58, 3-11.

Johnstone, M., \& Feeney, J. A. (2015). Individual differences in responses to workplace stress: The contribution of attachment theory. Journal of Applied Social Psychology, 45, 412-424.

Kastenbaum, R., Derbin, V., Sabatini, P., \& Artt, S. (1972). "The ages of me". Toward personal and interpersonal definitions of functional aging. The International Journal of Aging and Human Development, 3, 197-211.

Keyes, C. L., \& Westerhof, G. J. (2012). Chronological and subjective age differences in flourishing mental health and major depressive episode. Aging \& Mental Health, 16, 67-74

Kotter-Gruehn, D., Kornadt, A. E., \& Stephan, Y. (2015). Looking beyond chronological age: Current knowledge and future directions in the study of subjective age. Gerontology, 62, 86-93.

Kotter-Gruehn, D., Neupert, S. D., \& Stephan, Y. (2015). Feeling old today? Daily health, stressors, and affect explain day-to-day variability in subjective age. Psychology \& Health, 30, 1470-1485.

Kunze, F., Boehm, S. A., \& Bruch, H. (2011). Age diversity, age discrimination climate and performance consequences-a cross organizational study. Journal of Organizational Behavior, 32, 264-290.

Kunze, F., Raes, A. M., \& Bruch, H. (2015). It matters how old you feel: Antecedents and performance consequences of average relative subjec tive age in organizations. Journal of Applied Psychology, 100, 1511-1526.

Lang, F. R., \& Carstensen, L. L. (2002). Time counts: Future time perspective, goals, and social relationships. Psychology and Aging, 17, 125-139.

Miche, M., Wahl, H.-W., Diehl, M., Oswald, F., Kaspar, R., \& Kolb, M. (2014). Natural occurrence of subjective aging experiences in community-dwelling older adults. Journals of Gerontology Series B-Psychological Sciences and Social Sciences, 69, 174-187.

Montepare, J. M. (1996). Variations in adults' subjective ages in relation to birthday nearness, age awareness, and attitudes toward aging. Journal of Adult Development, 3, 193-203.

Montepare, J. M. (2009). Subjective age: Toward a guiding lifespan framework. International Journal of Behavioral Development, 33, 42-46.

Montepare, J. M., \& Lachman, M. E. (1989). "You're only as old as you feel": Self-perceptions of age, fears of aging, and life satisfaction from adolescence to old age. Psychology and Aging, 4, 73-78.

$\mathrm{Ng}, \mathrm{T}$. W., \& Feldman, D. C. (2008). The relationship of age to ten dimensions of job performance. Journal of Applied Psychology, 93, 392.

Nixon, A. E., Mazzola, J. J., Bauer, J., Krueger, J. R., \& Spector, P. E. (2011). Can work make you sick? A meta-analysis of the relationships between job stressors and physical symptoms. Work \& Stress, 25, 1-22.

OECD. (2008). Population Dynamics and Demographics. In OECD (Ed.), OECD Environmental Outlook to 2030, (pp. 65-73). Paris: OECD Publishing. doi: 10.1787/978926 4040519-en
OECD. (2018). Working age population (indicator). Retrieved from https:// data.oecd.org/pop/working-age-population.htm

Ohly, S., \& Schmitt, A. (2015). What makes us enthusiastic, angry, feeling at rest or worried? Development and validation of an affective work events taxonomy using concept mapping methodology. Journal of Business and Psychology, 30, 15-35.

Ohly, S., Sonnentag, S., Niessen, C., \& Zapf, D. (2010). Diary studies in organisation research. Journal of Personnel Psychology, 9, 79-93.

Paolacci, G., Chandler, J., \& Ipeirotis, P. G. (2010). Running experiments on Amazon Mechanical Turk. Judgment and Decision Making, 5, 411-419.

Ployhart, R. E., \& Vandenberg, R. J. (2010). Longitudinal research: The theory, design, and analysis of change. Journal of Management, 36, 94-120.

Posthuma, R. A., \& Campion, M. A. (2009). Age stereotypes in the workplace: Common stereotypes, moderators, and future research directions. Journal of Management, 35, 158-188.

Rabe-Hesketh, S., \& Skrondal, A. (2008). Multilevel and longitudinal modeling using Stata. College Statio: TX: Stata press.

Raudenbush, S. W., \& Bryk, A. S. (2002). Hierarchical linear models: Applications and data analysis methods. Newbury Park, CA: Sage.

Rudolph, C. W., Kunze, F., \& Zacher, H. (2019). Getting objective about subjective age: Introduction to a special issue. Work, Aging and Retirement, 5, 265-272.

Sapolsky, R. M., Krey, L. C., \& McEwen, B. S. (1986). The neuroendocrinology of stress and aging: The glucocorticoid cascade hypothesis. Endocrine Reviews, 7, 284-301.

Sato, S., Shimonaka, Y., Nakazato, K., \& Kawaai, C. (1997). A life-span developmental study of age identity: Cohort and gender differences. Japanese Journal of Developmental Psychology, 8, 88-97.

Schafer, M. H., \& Shippee, T. P. (2010). Age identity in context stress and the subjective side of aging. Social Psychology Quarterly, 73, 245-264.

Schwarz, N., \& Clore, G. L. (1983). Mood, misattribution, and judgments of well-being: Informative and directive functions of affective states. Journal of Personality and Social Psychology, 45, 513-523.

Schwarz, N., \& Clore, G. L. (2003). Mood as information: 20 years later Psychological Inquiry, 14, 296-303.

Seligman, M. E., \& Csikszentmihalyi, M. (2014). Positive psychology: An introduction flow and the foundations of positive psychology ( $p p$. 279-298). Dordrecht: Springer.

Sonnentag, S., \& Kuehnel, J. (2016). Coming back to work in the morning: Psychological detachment and reattachment as predictors of work engagement. Journal of Occupational Health Psychology, 21, 379-390

Statistics Canada. (2015). Canadian Community Health Survey (CCHS) - (2015). Retrieved from http://www23.statcan.gc.ca/imdb/p3Instr. pl?Function $=$ assemblelnstr $\& a=1 \& \&$ lang $=$ en\&ltem_ld $=238890 \#$ qb244241

Stephan, Y., Caudroit, J., \& Chalabaev, A. (2011). Subjective health and memory self-efficacy as mediators in the relation between subjective age and life satisfaction among older adults. Aging \& Mental Health, 15, 428-436.

Stephan, Y., Caudroit, J., Jaconelli, A., \& Terracciano, A. (2014). Subjective age and cognitive functioning: A 10-year prospective study. The American Journal of Geriatric Psychiatry, 22, 1180-1187.

Stephan, Y., Chalabaev, A., Kotter-Gruehn, D., \& Jaconelli, A. (2013). "Feeling younger, being stronger": An experimental study of subjective age and physical functioning among older adults. The Journals of Gerontology: Series B: Psychological Sciences and Social Sciences, $68 B, 1-7$

Stephan, Y., Sutin, A. R., \& Terracciano, A. (2015). Younger subjective age is associated with lower C-reactive protein among older adults. Brain, Behavior, and Immunity, 43, 33-36.

Stets, J. E., \& Burke, P. J. (2000). Identity theory and social identity theory Social Psychology Quarterly, 63, 224-237.

Stryker, S., \& Burke, P. J. (2000). The past, present, and future of an identity theory. Social Psychology Quarterly, 63, 284-297. 
Tajfel, H., \& Turner, J. C. (1986). The social identity theory of intergroup behaviour. In S. Worchel \& W. G. Austin (Eds.), Psychology of intergroup relations (pp. 7-24). Chicago, II: Nelson.

Teuscher, U. (2009). Subjective age bias: A motivational and information processing approach. International Journal of Behavioral Development, $33,22-31$.

Warr, P. (2000). Job performance and the ageing workforce. In N. Chmie (Ed.), Introduction to work and organizational psychology: A European perspective (pp. 407-423). Malden: Blackwell Publishing.

Watson, D., Clark, L. A., \& Tellegen, A. (1988). Development and validation of brief measures of positive and negative affect: The PANAS scales. Journal of Personality and Social Psychology, 54, 1063-1070.

Westerhof, G. J., Miche, M., Brothers, A. F., Barrett, A. E., Diehl, M., Montepare, J. M., ... Wurm, S. (2014). The influence of subjective aging on health and longevity: A meta-analysis of longitudinal data. Psychology and Aging, 29, 793-802.

Zacher, H., \& Frese, M. (2009). Remaining time and opportunities at work: Relationships between age, work characteristics, and occupational future time perspective. Psychology and Aging, 24, 487.

Zacher, H., \& Rudolph, C. W. (2019). Why do we act as old as we feel? The role of occupational future time perspective and core self-evaluations in the relationship between subjective age and job crafting behaviour. European Journal of Work and Organisation Psychology, 28(6), 831-844.

\section{Appendix A. Measurement items of the Work Events} Scale 1

Bono et al., 2013

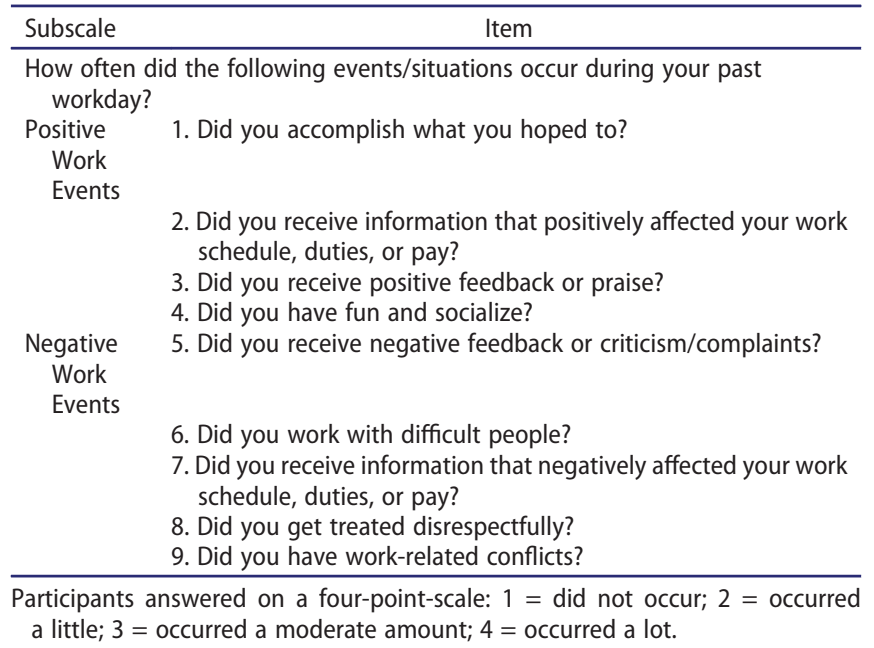

